\title{
Alterações morfofisiológicas e crescimento de helicônias em função de diferentes ambientes de sombreamento
}

\author{
Rafaela Ribeiro de Souza ${ }^{*}$, Markilla Zunete Beckmann Cavalcante ${ }^{2}$, Everaldo Moreira Silva', \\ Genilda Canuto Amaral ${ }^{3}$, Leonardo Pereira Silva Brito², Rodrigo Cirqueira Avelino² \\ 'Universidade Federal do Piauí, Bom Jesus, Pl, Brasil \\ ${ }^{2}$ Universidade Federal Vale de São Francisco, Petrolina, PE, Brasil \\ 3Universidade de Brasília, Brasilia, DF, Brasil \\ * Autor correspondente, e-mail: rafaela_o2@hotmail.com
}

\begin{abstract}
Resumo
A utilização de sombreamento artificial tem sido amplamente empregada na produção de mudas, flores e plantas ornamentais, com o objetivo de minimizar os danos provenientes do excesso de luminosidade. Esta pesquisa avaliou o efeito de diferentes ambientes sombreados [0\% (pleno sol); $35 \%$ e 50\% de sombreamento e sobreposição de telas de $35 \%+50 \%$ ] sobre os aspectos morfofisiológicos e de crescimento de Heliconia psittacorum cv. Golden Torch e Heliconia bihai cv. Humilis em Bom Jesus-PI, no período de agosto de 2012 a julho de 2013. O delineamento experimental utilizado foi inteiramente casualizado com os tratamentos distribuídos em esquema fatorial de $2 \times 4$ (Espécie $\times$ Sombreamento) e seis repetições. As plantas de H. bihai cv. Humilis apresentaram maior área foliar comparada com a H. psittacorum cv. Golden Torch no tratamento correspondente a sobreposição de telas de $35 \%+50 \%$, indicando que as duas espécies possuem diferentes mecanismos morfológicos de adaptação ao ambiente sombreado. As plantas cultivadas em pleno sol (0\% de sombra) apresentaram menor crescimento (altura e área foliar) e menor teor de clorofilas. O sombreamento proporcionado pela tela de $50 \%$ é eficiente para a obtenção do crescimento e estabelecimento desejável de H. bihai cv. Humilis e H. psittacorum cv. Golden Torch cultivadas em vaso.
\end{abstract}

Palavras-chave: floricultura tropical, pigmentos fotossintéticos, intensidade luminosa

\section{Growth and changes on morphology and physiology of heliconias according to different shading environments}

\begin{abstract}
The use of shading has been widely used for production of seedlings, flowers and ornamental plants, aiming to minimize the damage from the excess of luminosity. This research evaluated the effect of different shaded environments [0\% (full sun); $35 \%$ and $50 \%$ of shading and overlapping screens of $35 \%+50 \%$ ] on morphophysiological aspects and growth of Heliconia psittacorum cv. Golden Torch and Heliconia bihai cv. Humilis in Bom Jesus county, Piaui state, Brazil, from August, 2012 to July, 2013. The experiment was carried out in a completely randomized design with treatments arranged in a 2 $\times 4$ (Species $x$ Shading) factorial, with six repetitions. Plants of $\mathrm{H}$. bihai $\mathrm{cv}$. Humilis showed higher leaf area compared to H. psittacorum cv. Golden Torch when the corresponding overlapping screens of $35 \%+50 \%$ was applied, indicating that the two species have different morphological mechanisms for adaptation in shaded environments. Plants grown in full sun (0\% of shade) presented lower growth (height and leaf area) and lower chlorophyll content. The $50 \%$ of shading providedwas effective to achieve the desired establishment and growth of H. bihai cv. Humilis and H.Psittacorum cv. Golden Torch, grown in pots.
\end{abstract}

Keywords: tropical flowers, photosynthetic pigments, luminous intensity 


\section{Introdução}

As plantas desenvolvem uma série de mecanismos que thes permitem manter um equilíbrio entre a energia absorvida pela luz e a sua utilização, através da fixação de carbono durante a fotossíntese. Em certas condições ambientais, a energia luminosa absorvida pode ser superior à capacidade que a planta tem para utilizá-la, criando um desequilíbrio que pode promover à fotoinibição ou, em condições de baixa luminosidade, levar à deficiência de luz. Em ambas condições o crescimento é severamente restringido (Ivanov et al., 2008).

O clima, a água e os nutrientes são apontados como os principais fatores que influenciam a produtividade agrícola, no entanto, água e nutrientes do solo são fáceis de controlar, por meio da irrigação e fertilização. Em contrapartida, a intensidade de luz lum dos fatores climáticos mais importantes ao crescimento das plantas) é bem mais difícil de controlar (Wang et al., 2007).

A helicônia, pertencente à ordem das Zingiberales, é uma das espécies de flores tropicais mais importantes, produzidas e comercializadas em grande escala, devido principalmente à beleza de suas brácteas, inusitadas formas nas diferentes espécies, resistência ao transporte e durabilidade pós-colheita (Rodríguez, 2013).

As Zingiberales são provenientes de regiões tropicais onde a incidência de radiação solar é alta, porém, essas regiões também apresentam imensas áreas com florestas tropicais úmidas e sombreadas (Meleiro et al., 2003).

A caracterização quanto à tolerância inter e intra-específica em diferentes ambientes sombreados varia tanto à nível da quantidade de luz, quanto entre as espécies, promovendo alterações morfofisiológicas como: expansão da área foliar, altura de planta, quantidade de clorofila total, clorofila $a$ e b. Essas diferenças ocorrem como resultado das alterações adaptativas em resposta a estas condições (Lichtenthaler et al., 2007).

Não há informações referentes à tolerância das espécies de Heliconia psittacorum cv. Golden Torch e Heliconia bihai cv. Humilis ao sombreamento e suas características morfofisiológicas em resposta ao estresse pela luz.
Portanto, é de extrema importância determinar o grau de tolerância à sombra de tais espécies e examinar a influência de diferentes ambientes com sombreamento sobre o crescimento, possibilitando melhor manejo do ambiente de produção.

Diante do exposto, o objetivo deste trabalho foi verificar as alterações morfofisiológicas e o crescimento de $H$. psittacorum cv. Golden Torch e H. bihai cv. Humilis em diferentes ambientes sombreados.

\section{Material e Métodos}

O experimento foi conduzido no Setor de Floricultura do Campus Prof. ${ }^{a}$ Cinobelina Elvas (CPCE) da Universidade Federal do Piauí (UFPI), situado na cidade de Bom Jesus-PI, durante o período de agosto de 2012 a julho de 2013. O município está localizado na latitude 904'45" sul e longitude $44^{\circ} 18^{\prime} 46^{\prime \prime}$ oeste, a uma altitude de 322 metros, é pertence à região Sul Piauiense com clima quente e úmido, classificado por Köppen como Cwa, com precipitação pluvial média entre 900 e $1200 \mathrm{~mm}^{\circ} \mathrm{no}^{-1}$ distribuídos entre os meses de dezembro e abril e temperatura média anual de $26,6^{\circ} \mathrm{C}$ (Viana et al., 2002).

Os rizomas utilizados para propagação de Heliconia psittacorum cv. Golden Torch e Heliconia bihai $\mathrm{cv}$. Humilis foram adquiridos na coleção de helicônias do CPCE/UFPI. Inicialmente foi realizada a padronização dos rizomas, seguida de lavagem e imersão em solução contendo hipoclorito de sódio (1\%) durante 15 min. Posteriormente, os rizomas foram cultivados em recipiente tipo saco de polietileno (volume 3,0 L) preenchido com areia e esterco bovino nas proporções de 1:1 (v/v). As mudas foram acondicionadas em ambiente tipo telado, com 50\% de sombreamento durante 118 dias (Beckmann-Cavalcante et al., 2011).

O transplante das mudas para vasos com capacidade de $20 \mathrm{~L}$, foi realizado quando as mudas apresentavam em torno de 3 a 4 folhas. Os vasos foram preenchidos com substrato contendo areia e esterco bovino na proporção 1:1 (v/v) e adicionados 45 g/vaso de fósforo (superfosfato simples). A adubação com nitrogênio (uréia 45\%) e potássio (cloreto de potássio $58 \%$ de $\mathrm{K}_{2} \mathrm{O}$ ) foi dividida em três 
aplicações de 40 g/vaso, aos 45, 90 e 150 dias após 0 transplante (Beckmann-Cavalcante et al., 2015).

As plantas foram organizadas ao acaso em quatro grupos distribuídos de acordo com 0 ambiente de sombreamento: $1=0 \%$ de sombreamento (pleno sol); $2=35 \%$ de sombreamento; $3=50 \%$ de sombreamento e 4 $=$ sobreposição de telas de $35 \%+50 \%$. Em todos os tratamentos com sombreamento, as plantas foram dispostas sob uma armação de madeira revestida na parte superior e nas laterais, com telas de polietileno de cor preta. Cada armação foi dimensionada em $9 \mathrm{~m}$ de comprimento $\times 5 \mathrm{~m}$ de largura e $2 \mathrm{~m}$ de altura.

Foi adotado um sistema de irrigação por gotejamento com emissores do tipo autocompensante, com vazão nominal de $4 \mathrm{~L}$ $\mathrm{h}^{-1}$, os quais foram previamente avaliados sob condições normais de operação, apresentando coeficiente de uniformidade de distribuição de $97,8 \%$. Os gotejadores foram acoplados às linhas de irrigação compostas por tubos de polietileno de $16 \mathrm{~mm}$. A irrigação foi conduzida diariamente até atingir a capacidade de campo.

Durante a condução do experimento, foi detectada a incidência de cochonilhas (Dysmicoccus brevipes (Cockerell)), lagartas desfolhadoras (Antichloris eriphia (Fabricius)) e mosca-branca (Aleuro thrixusfloccosus (Maskell)) nas plantas de helicônias em pleno florescimento.

A infestação ocorreu principalmente no ambiente com sobreposição das telas de $35 \%$ $+50 \%$. Como medida de controle, foi realizada quatro aplicações de Malatol ${ }^{\circledR}$, num intervalo de quinze dias, na concentração de $5 \mathrm{ml}$ por litro de solução.

Os dados meteorológicos referentes à temperatura do ar, umidade relativa do ar $e$ intensidade luminosa foram monitorados diariamente (Figura 1). A temperatura e umidade relativa do ar foram obtidas através de termo-higrômetro digital (Quimis ${ }^{\circledR}$ ) instalado na parte central de cada ambiente, com o sensor disposto a 1,50 m de altura do solo; a intensidade luminosa foi aferida através de luxímetro digital (Instrutherm ${ }^{\circledR}$ ).

O delineamento experimental adotado foi o inteiramente casualizado com os tratamentos distribuídos em esquema fatorial $2 \times 4$, referentes a duas espécies de helicônias (Heliconia psittacorumcr. Golden Torch e Heliconia bihai cv. Humilis) e quatro ambientes de sombreamento [0\% de sombreamento (pleno sol); $35 \%$; $50 \%$ e sobreposição das telas de $35 \%$ $+50 \%$ ]. Foram utilizados seis repetições e dois vasos por parcela, perfazendo um total de 96 vasos.

Aos 210 dias após o transplante foram avaliadas:Altura de planta $(\mathrm{cm})$; obtida com auxílio de trena milimetrada, medindo-se do nível superior do vaso ao ápice da planta; Área foliar $\left(\mathrm{cm}^{2}\right)$ : obtida a partir de medidas não destrutivas, medindo-se a maior largura e maior comprimento do limbo foliar em três posições determinadas nas plantas (duas do ápice, duas do meio e duas inferiores) e calculado pelas equações baseadas em Pinto (2007); Número de perfilhos emitidos por rizoma: obtido mediante a contagem dos perfilhos emitidos; Índices de Clorofilas $a, b$ e total: obtidas por meio de três leituras por folha (na ponta e nas duas laterais de cada folha) em três folhas por planta, maduras e sadias, utilizando o aparelho clorofilômetro (Falkerß); Relação clorofila a e b: obtida por meio da razão entre índices de clorofila a/ clorofila b; Relação entre índice de clorofila total e área foliar: obida por meio da razão entre índice de clorofila total/ área foliar.

Os dados obtidos foram submetidos à análise de variância para diagnóstico de efeito significativo em espécie de helicônias e ambientes com sombreamento. Quando o efeito foi significativo, as médias foram comparadas pelo teste de Tukey $(p<0,05)$. As análises foram realizadas pelo programa computacional Sistema para Análise de Variância - SISVAR (Ferreira, 2008).

\section{Resultados e Discussão}

Ainteração entre os diferentes ambientes de sombreamento e as diferentes espécies de helicônias H. psittacorum cv. Golden Torch e H. bihai $\mathrm{cv}$. Humilis influenciou significativamente a área foliar e razão índice de clorofila total por área foliar (Tabela 1).

A espécie $H$. bihai $\mathrm{cv}$. Humilis apresentou maior área foliar comparada 
com a $\mathrm{H}$. psittacorum cv. Golden Torch (Figura 2). No entanto, a diferença quanto ao comportamento das espécies nos diferentes ambientes de sombreamento só ocorreu no tratamento correspondente a sobreposição de
$35 \%+50 \%$. Assim, plantas de $H$. bihai cv. Humilis e H. psittacorum cv. Golden Torch parecem possuir diferentes mecanismos morfológicos de adaptação ao estresse provocado pelo ambiente sombreado.
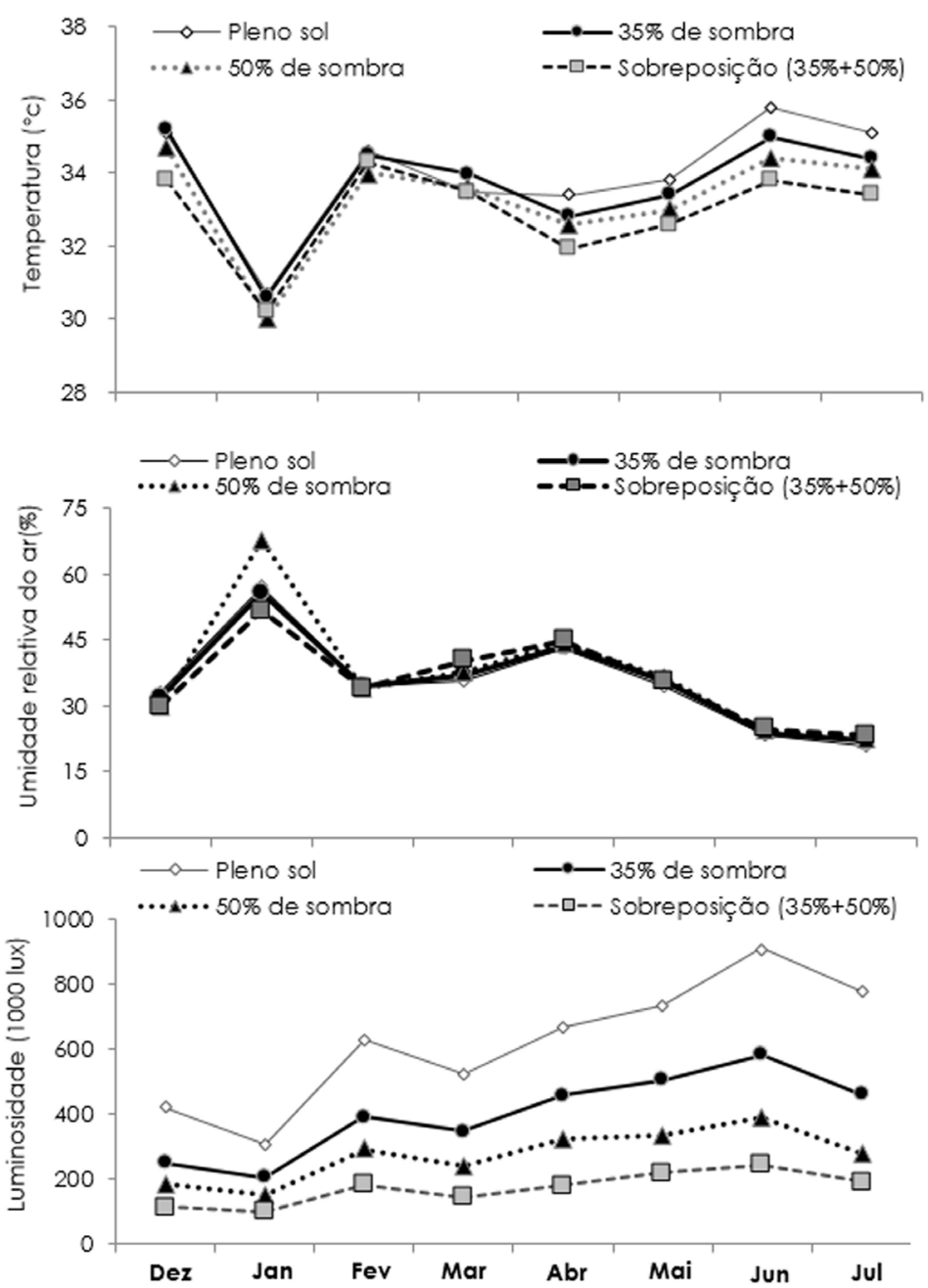

Figura 1. Médias referentes à temperatura $\left({ }^{\circ} \mathrm{C}\right)$, umidade relativa do ar $(\%)$ e luminosidade (Lux) obtida nos diferentes ambientes de sombreamento durante 0 período experimental, Bom Jesus, Estado do Piauí, 2013.

Tabela 1. Resumo da análise de variância da altura de planta (H), área foliar (AF), número de perfilhos (N perf), índice de clorofila A (Chl a), índice de clorofila B (Chl b), índice de clorofila total (Chl total), razão clorofila A/ clorofila B (Chl a/ Chl b), razão índice de clorofila total/ área foliar (Clo total/AL) em função dos diferentes ambientes de sombreamento (\%SH) e espécies de helicônia. Bom Jesus, PI, 2014.

\begin{tabular}{|c|c|c|c|c|c|c|c|c|}
\hline $\begin{array}{l}\text { CAUSA DE } \\
\text { VARIÂNCIA }\end{array}$ & $\begin{array}{c}\mathrm{H} \\
-\mathrm{cm}-\end{array}$ & $\begin{array}{c}\mathrm{AF} \\
-\mathrm{cm}^{2}-\end{array}$ & $\begin{array}{c}\text { N perf } \\
---\end{array}$ & $\begin{array}{c}\text { Chl a } \\
---\end{array}$ & $\begin{array}{c}\text { Chl b } \\
--\end{array}$ & $\begin{array}{c}\text { Chl total } \\
---\end{array}$ & $\underset{---}{C h l ~ a / C h l ~ b ~}$ & Chl total/AL \\
\hline$\% \mathrm{SH}$ ('F') & $84,1^{* *}$ & $32,9^{* *}$ & $7,9^{* *}$ & $16,3^{* *}$ & $20,1^{* *}$ & $23,5^{* *}$ & $6,3^{* *}$ & $107,6^{* *}$ \\
\hline Espécie ('F') & $4,5^{*}$ & $19,8^{* *}$ & $1,9 \mathrm{~ns}$ & $28,0^{* *}$ & $110,7^{* *}$ & $76,1^{* *}$ & $52,9 * *$ & $37,4^{* *}$ \\
\hline cv. Humilis & $90,6 \mathrm{~b}$ & 1519,8 & $12,4 a$ & $38,5 \mathrm{~b}$ & $14,5 \mathrm{~b}$ & $53,1 \mathrm{~b}$ & $2,7 \mathrm{a}$ & 0,07 \\
\hline cv. Golden Torch & $97,8 a$ & 885,2 & $11,4 a$ & 44,1 a & $23,2 a$ & $67,3 \mathrm{a}$ & $1,9 \mathrm{~b}$ & 0,14 \\
\hline DMS & 6,8 & 287,6 & 1,4 & 2,1 & 1,6 & 3,2 & 0,22 & 0,02 \\
\hline$\% \mathrm{SH} \times \operatorname{Esp}(' \mathrm{~F}$ ') & $0,4 \mathrm{~ns}$ & $4,8^{* *}$ & $1,0 \mathrm{~ns}$ & $1,1 \mathrm{~ns}$ & $1,3 \mathrm{~ns}$ & $0,7 \mathrm{~ns}$ & $0,5 \mathrm{~ns}$ & $10,0^{* *}$ \\
\hline CV \% & 12,4 & 40,9 & 20,3 & 8,7 & 15,0 & 9,3 & 16,0 & 34,4 \\
\hline
\end{tabular}




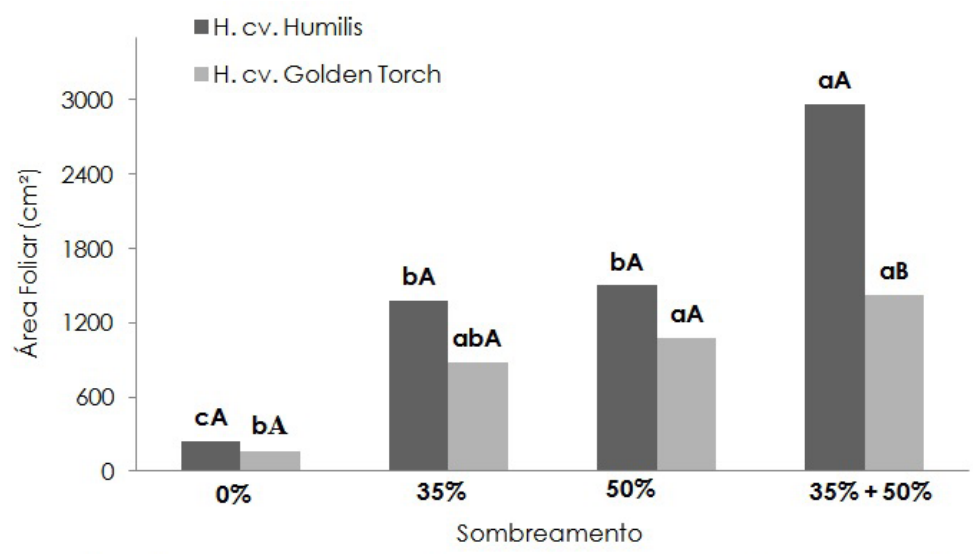

Figura 2. Área foliar de plantas de Heliconia psittacorum cv. Golden Torch e Heliconia bihai cv. Humilis cultivadas em diferentes ambientes com sombreamento. Médias seguidas pela mesma letra não diferem entre si, a $5 \%$ de probabilidade, pelo teste Tukey. As letras maiúscula comparam os diferentes ambientes de sombreamento e minúscula comparam as espécies.

Ambientes sombreados incrementaram significativamente a área foliar. Este aumento pode ser reflexo de um mecanismo de adaptação das folhas à condições de pouca luminosidade, o que possibilita uma maior captação de luz (Miralles et al., 2011). Neste sentido, tais resultados indicam a capacidade das plantas de helicônias de adequação e maximização de absorção de luz em condições de pouca luminosidade. Portanto, a plasticidade fenotípica existente, independente das condições de sol e sombra, é de elevada importância para sobrevivência e crescimento em ambientes heterodinâmicos (Mielke \& Schaffer, 2010).

A relação índice de clorofila total por área foliar (Figura 3) foi maior em plantas cultivadas em $0 \%$ de sombreamento (pleno sol), diferindo dos demais tratamentos. As espécies H. pstitacorum cv. Golden Torch e H. bihai cv. Humilis obtiveram comportamento similar, apresentando diferença significativa apenas a nível de $0 \%$ de sombreamento.

Folhas de plantas submetidas ao sombreamento apresentam maior concentração de clorofila do que as folhas de plantas cultivadas em pleno sol. Porém, se o conteúdo for expresso por unidade de área foliar a concentração é menor nas folhas de sombra. Portanto, folhas de sombra investem mais energia na produção de pigmentos fotossintéticos, permitindo uma otimização na utilização da intensidade de luz incidente (Deng et al., 2012a).

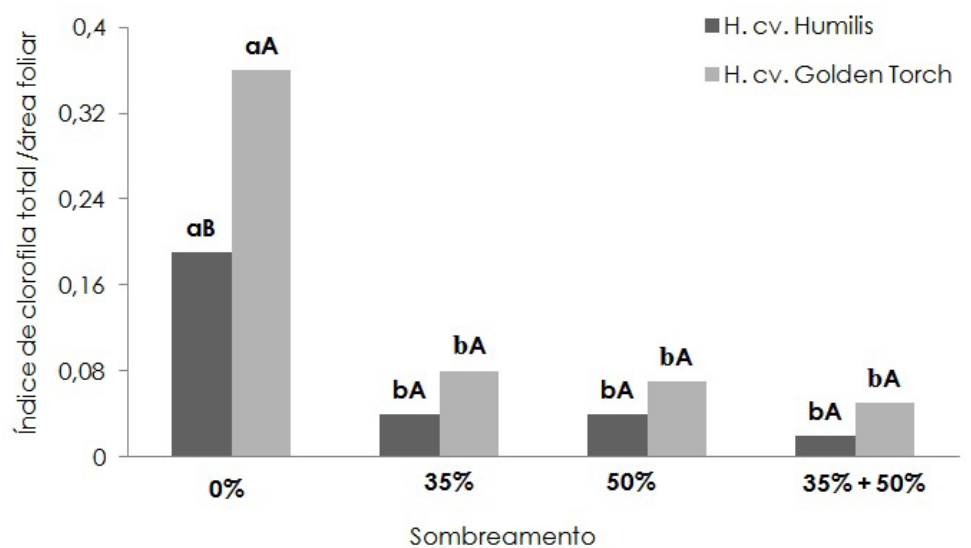

Figura 3. Relação índice de clorofila total por área foliar em plantas Heliconia psittacorum cv. Golden Torch e Heliconia bihai cv. Humilis cultivadas em diferentes ambientes com sombreamento. Médias seguidas da mesma letra não diferem entre si, a 5\% de probabilidade, pelo teste Tukey.As letras maiúscula comparam os diferentes ambientes de sombreamento e minúscula comparam as espécies. 
Para a variável altura de plantas a espécie H. psittacorum cv. Golden Torch obteve maiores valores, quando comparada a espécie $\mathrm{H}$. bihai $\mathrm{cv}$. Humilis, nos tratamentos correspondentes a $35 \%$ e $50 \%$ de sombreamento. As plantas cultivadas no ambiente com sobreposição de telas de $35 \%+50 \%$ obtiveram maior altura, quando comparado aos demais ambientes (Figura 4). Nota-se que, o sombreamento proporcionou a obtenção de plantas mais altas. Este resultado pode estar relacionado a uma provável ativação do fototropismo ou mesmo um possível estiolamento das plantas.

Há evidências de que o menor crescimento obtido por plantas cultivadas em pleno sol seja decorrente de elevadas temperaturas na superfície foliar, e consequentemente, o aumento na transpiração e na atividade respiratória, o que estimularia o fechamento dos estômatos, reduzindo a fixação de carbono e aumentando o consumo de fotoassimilados (Taiz \& Zeiger, 2009).

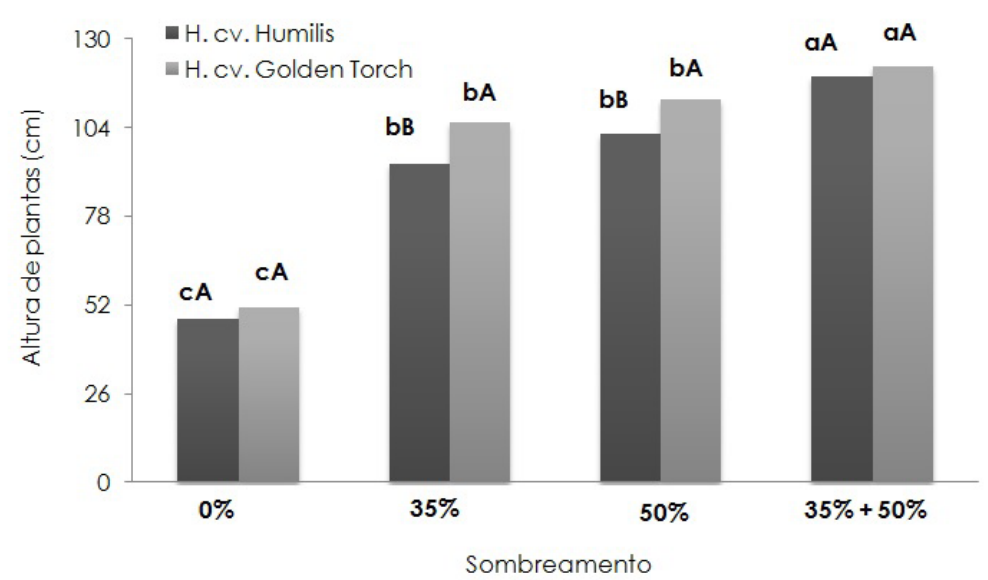

Figura 4. Médias para altura de plantas Heliconia psittacorum cv. Golden Torch e Heliconia bihai cv. Humilis cultivadas em diferentes ambientes com sombreamento. Médias seguidas da mesma letranão diferem entre si, a $5 \%$ de probabilidade, pelo teste Tukey. As letras maiúscula comparam os diferentes ambientes de sombreamento e minúscula comparam as espécies.

O estresse promovido pelo calor é um fator importante, que dependendo da espécie e estágio fenológico podem afetar a taxa de desenvolvimento das plantas, podendo aumentar até certo limite e depois diminuir. Em condições de elevadas temperaturas, a atividade fotossintética reduz drasticamente, devido a redução ou mesmo a interrupção da atividade do fotossistema II. Portanto, qualquer interrupção na fotossíntese pode afetar diretamente no crescimento das plantas (Wahid et al., 2007; Vaid \& Runkle, 2013). É evidente que altas taxas de temperatura associadas aos elevados níveis de luminosidade (Figura 1) registrados no ambiente com $0 \%$ de sombreamento (pleno sol) favoreceram ao menor crescimento das plantas.

Os tratamentos que proporcionaram maior perfilhamento foram obtidos em ambientes sombreados (Figura 5). O menor número de perfilhos (9) ocorreu no tratamento com $0 \%$ de sombra (pleno sol). Durante a condução do experimento foi observado que as plantas cultivadas em pleno sol $10 \%$ de sombreamento) emitiam seus perfilhos, porém o excesso de incidência luminosa provocava a queimadura dos brotos, levando-os a morte, tal situação explica o menor número de perfilhos no tratamento com $0 \%$ de sombra.

O número de perfilhos é uma característica importante, visto que, quanto maior o número de brotações maior será o número de folhas que captam energia solar produzindo matéria orgânica por meio da fotossíntese (Assis et al., 2009). Os ambientes com $35 \%, 50 \%$ e sobreposição de sombrites de $35 \%+$ $50 \%$ apresentaram maior número de perfilhos. No entanto, o ambiente com sobreposição de sombrites de $35 \%+50 \%$ foi similar ao tratamento com $0 \%$ de sombreamento. Este resultado indica que a redução no número de perfilhos pode estar relacionada ao alto-sombreamento 
proporcionado na base da planta, estimulando - crescimento dos perfilhos já existentes e inibindo a diferenciação das gemas em novos perfilhos.

A produção de pigmentos fotossintéticos foi afetada significativamente pelos diferentes níveis de sombreamento, (Figura 6 a; b e c). Verificou-se ainda, que os índices de Chla, Chlb e Chl total foram superiores nos tratamentos correspondente à $50 \%$ de sombreamento e sobreposição de telas de $35 \%+50 \%$. Estes resultados estão de acordo com os obtidos por Deng et al. (2012b), que ao avaliar o efeito do sombreamento sobre as características relacionadas a fotossíntese e estrutura dos cloroplastos da espécie jasmim (dupla pétala e multi pétala), obtiveram um incremento no conteúdo de clorofilas $a, b$ e total em função do sombreamento.

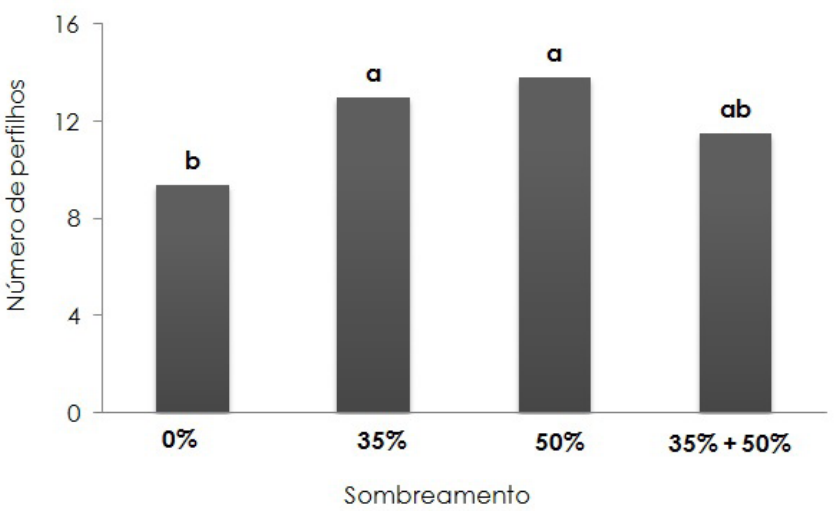

Figura 5. Número de perfilhos de Heliconia psittacorum cv. Golden Torch e Heliconia bihai cv. Humilis cultivadas em diferentes ambientes com sombreamento. Médias seguidas da mesma letra não diferem entre si, a $5 \%$ de probabilidade, pelo teste Tukey.

(a)

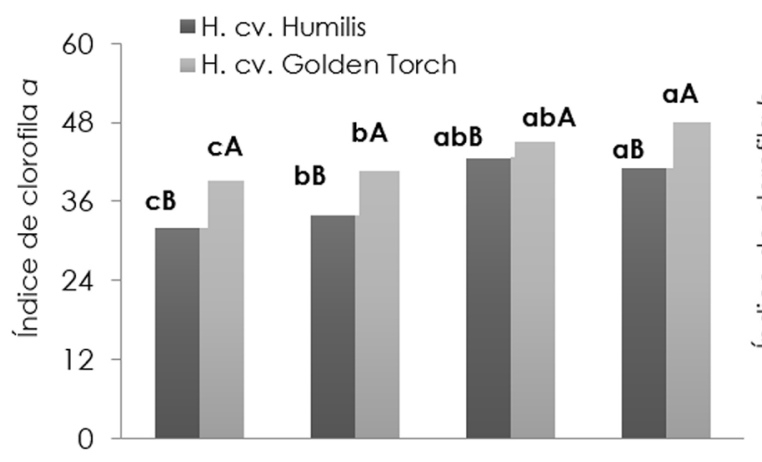

(c)

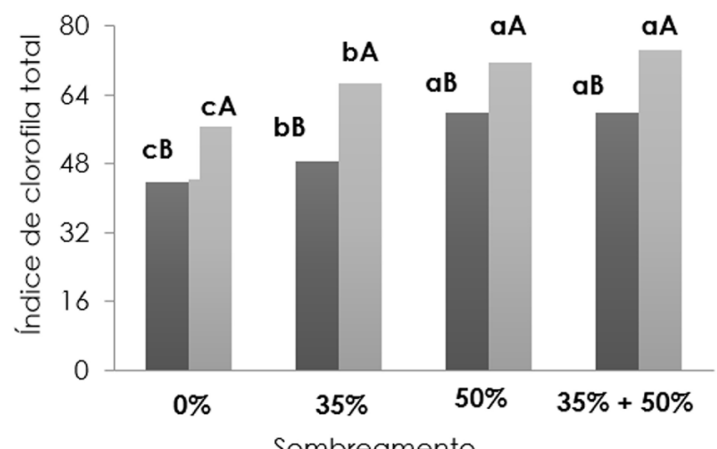

(b)

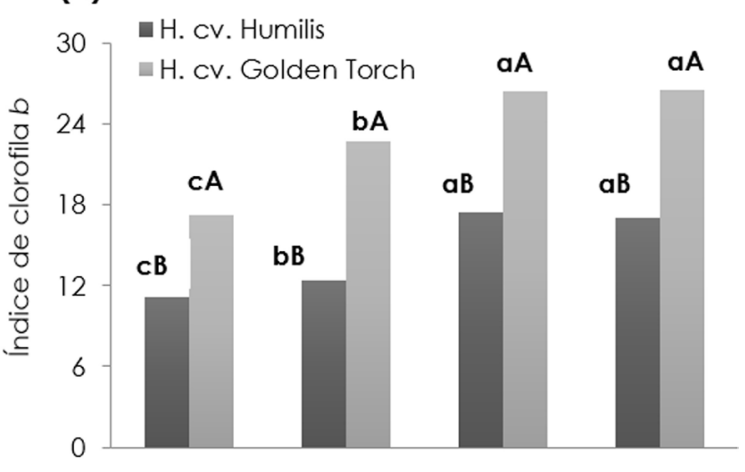

(d)

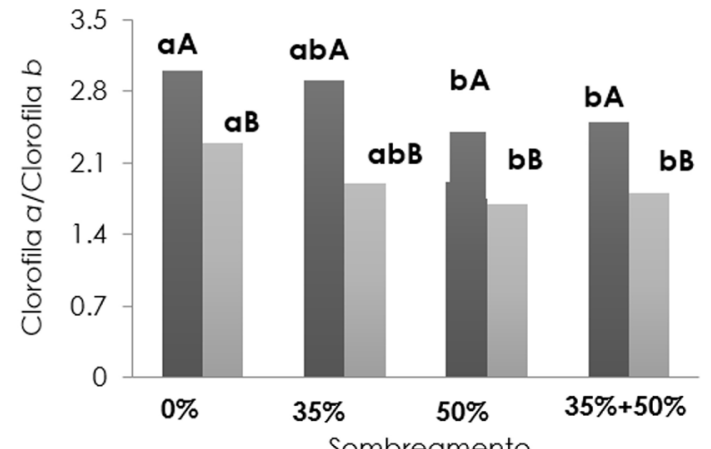

Figura 6. a) Índice de clorofila a; b) Índice de clorofila b; c) Índice de clorofila total; d) Relação índice de clorofila a e b de plantas de Heliconia psittacorum cv. Golden torch e Heliconia bihai cv. Humilis cultivadas em diferentes ambientes com sombreamento. Médias seguidas da mesma letra não diferem entre si, a $5 \%$ de probabilidade, pelo teste de Tukey. As letras maiúscula comparam os diferentes ambientes de sombreamento e minúscula comparam as espécies. 
O conteúdo de clorofila na folha de plantas crescidas em ambientes sombreados, é uma referência eficaz para explicar a influência do mecanismo de otimização de absorção de luz por pigmentos fotossintéticos (Daí et al., 2009).

A diminuição do conteúdo de Chla, b e total verificado no tratamento a pleno sol, indica uma possível degradação de clorofilas pelo excesso de irradiância. Dessa forma, ambientes de pleno sol podem prejudicar ou inativar o sistema fotossintético (Fotoinibição) de plantas de H. psittacorum cv. Golden Torch e H. bihai cv. Humilis. Ao passo que, o aumento no teor de Chla, b e total em ambientes sombreados, provêm de uma adaptação das plantas a menor quantidade de luz, a fim de manter a taxa fotossintética em níveis adequados (Deng et al., 2012a).

A razão índice de Chla/ Chlb (Figura 6 d), sofreu uma redução significativa nos diferentes ambientes sombreados. No entanto, - tratamento correspondente a $35 \%$ de sombreamento não diferiu do ambiente a pleno sol. A menor relação obtida nos tratamentos com $50 \%$ de sombreamento e sobreposição de telas de $35 \%+50 \%$ ocorreu devido principalmente ao aumento significativo do conteúdo de clorofila $b$ (Kouřil et al., 2012).

De acordo com Ruberti et al. (2012) o aumento da clorofila $b$ nas folhas submetidas ao sombreamento é uma característica importante, porque esta capta energia de menores comprimentos de onda e a transfere para a clorofila a, que efetivamente atua nas reações fotoquímicas da fotossíntese e representa um mecanismo de adaptação à condição de menor intensidade luminosa.

\section{Conclusões}

O ambiente de sombreamento proporcionado pela tela de $50 \%$ é eficiente para a obtenção do crescimento e estabelecimento desejável de H. psittacorum cv. Golden Torch e $H$. bihai $\mathrm{cv}$. Humilis cultivadas em vaso.

O sombreamento influencia significativamente o contéudo de pigmentos fotossinteticos e o crescimento das plantas de H. psittacorum cv. Golden Torch e H. bihai cv. Humilis, ao passo que, plantas mantidas em pleno sol sofrem fotoinibição pelo excesso de radiação luminosa.

\section{Referências}

Assis, A.M., Faria R.T., Unemoto, L.K., Colombo, L.A., Lone, A.B. 2009. Aclimatização de bastãodo-imperador (Etlinger aelatior) em substratos à base de coco. Acta Scientiarum. Agronomy $31: 43-47$.

Beckmann-Cavalcante, M.Z., Amaral, G.C., Silva, A.A., Cavalcante, I.H.L., Lima, M. P.D. 2011. Alternative substrates for production of Heliconia psittacorum L. seedlings under shade and open field conditions. African Journal of Biotechnology 10: 1527-1527.

Beckmann-Cavalcante, M.Z., Amaral, G.C., Avelino, R.C., Silva, A.A., Silva, A.S., Oliveira, J.B.S. 2015. Produção de inflorescências de helicônia cv. Golden Torch sob adubação nitrogenada e potássica. Comunicata Scientiae 6: 65-73.

Daí, Y., Shen, Z., Liu, Y., Wang, L., Hannaway, D., LU, H. 2009. Effects of shade treatments on the photosynthetic capacity, chlorophyll fluorescence, and chlorophyll content of Tetrastigma hemsleyanum Diels et Gilg. Environmental and Experimental Botany 65: 177182.

Deng, Y., Shao, Q., Li , C., Ye, X., Tang, R. 2012a. Differential responses of double petal and multi petal jasmine to shading: II. Morphology, anatomy and physiology. Scientia Horticulturae 144: 19-28.

Deng, Y., Li, C., Shao, Q., Ye, X., She, J. 2012b. Differential responses of double petal and multi petal jasmine to shading: I. Photosynthetic characteristics and chloroplast ultrastructure. Plant Physiology and Biochemistry 55: 93-102.

Ferreira, D.F. 2008. SISVAR: Um programa para análises e ensino de estatística. Revista Symposium 6: 36-41.

Ivanov, A., Hurry, V., Sane, P., Öquist, G., Huner, N. 2008. Reaction centre quenching of excess light energy and photoprotection of photosystem II. Journal of Plant Biology 51: 85-96.

Kouřil, R., Dekker, J.P., Boekema, E.J. 2012. Supramolecular organization of photosystem II in green plants: Review. Biochimica et Biophysica Acta 1817: 2-12.

Lichtenthaler, H.K., Marek, M.V., Kalina, J., Urban, O. 2007. Differences in pigment composition, photosynthetic rates and chlorophyll fluorescence images of sun and shade leaves of four tree species. Plant Physiology and Biochemistry 45: 577- 588. 
Meleiro, M. 2003. Desenvolvimento de zingiberales ornamentais em diferentes condições de luminosidade. 71f. (Dissertação de Mestrado) Instituto Agronômico de Campinas, Campinas, Brasil.

Mielke, M.S., Schaffer, B. 2010. Photosynthetic and growth responses of Eugenia uniflora L. seedlings to soil flooding and light intensity. Environmental and Experimental Botany 68: 113-121.

Miralles, J., Martínez-Sánchez, J. J., Franco, J. A., Bañón, S. 2011. Rhamnus alaternus growth under four simulated shade environments: Morphological, anatomical and physiological responses. Scientia Horticulturae 127: 562-570.

Pinto, S.A. 2007. Heliconia psittacorum L.: propagação e adubação na fase inicial de cultivo. 92f. (Dissertação de Mestrado) Universidade Federal de Viçosa, Viçosa, Brasil.

Rodríguez, F. M. S. 2013. Cultivo del género heliconia. Cultivos Tropicales 34: 24-32.

Ruberti, I., Sessa, G., Ciolfi, A., Possenti, M., Carabelli, M., Morelli, G. 2012. Plant adaptation to dynamically changing environment: The shade avoidance response. Biotechnology Advances 30: 1047-1058.

Taiz, L., Zeiger, E. 2009. Fisiologia vegetal. Artmed, Porto Alegre, Brasil. 819p.

Vaid, T.M., Runkle, E.S. 2013. Developing $\square$ owering rate models in response to mean temperature for common annual ornamental crops. Scientia Horticulturae 161: 15-23.

Viana, T.V.A., Vasconcelos, D.V., Azevedo, B.M., Souza, V.F. 2002. Estudo da aptidão agroclimática do Estado do Piauí para o cultivo da aceroleira. Ciência Agronômica 33: 61-64.

Wahid, A., Gelani, S., Ashrof, M., Forolad, M. R. 2007. Heat Tolerance in plants: An overview. Environmental and Experimental Botany 61: 199223.

Wang, H., Wang, F.L., Wang, G., Majourhat, K. 2007. The responses of photosynthetic capacity, chlorophyll fluorescence and chlorophyll content of nectarine (Prunus persica var. Nectarina Maxim) to greenhouse and field grown conditions. Scientia Horticuturae 112: 66-72. 